\title{
Coronavirus COVID-19 impacts to dentistry and potential salivary diagnosis
}

\author{
Robinson Sabino-Silva ${ }^{1,2} \cdot$ Ana Carolina Gomes Jardim ${ }^{3} \cdot$ Walter L. Siqueira ${ }^{1}$ (D) \\ Received: 15 February 2020 / Accepted: 17 February 2020 / Published online: 20 February 2020 \\ (C) Springer-Verlag GmbH Germany, part of Springer Nature 2020
}

\section{Summary}

A novel coronavirus (COVID-19) is associated with humanto-human transmission. The COVID-19 was recently identified in saliva of infected patients. In this point-of-view article, we discuss the potential of transmission via the saliva of this virus. The COVID-19 transmission via contact with droplets and aerosols generated during dental clinical procedures is expected. There is a need to increase investigations to the detection of COVID-19 in oral fluids and its impact on the transmission of this virus, which is crucial to improve effective strategies for prevention, especially for dentists and healthcare professionals that perform aerosol-generating procedures. Saliva can have a pivotal role in the human-to-human transmission, and non-invasive salivary diagnostics may provide a convenient and cost-effective point-of-care platform for the fast and early detection of COVID-19 infection.

\section{Current point of view}

The present outbreak of the 2019 coronavirus strain (COVID19) constitutes a public health emergency of global concern [1]. International centers for disease control and prevention are monitoring this infectious disease outbreak; symptoms of COVID-19 infection include fever, cough, and acute

Robinson Sabino-Silva, Ana Carolina Gomes Jardim and Walter L. Siqueira contributed equally to this work.

Walter L. Siqueira

walter.siqueira@usask.ca

1 College of Dentistry, University of Saskatchewan, Saskatoon, Saskatchewan, Canada

2 Department of Physiology, Institute of Biomedical Sciences, Federal University of Uberlandia, Uberlandia, Minas Gerais, Brazil

3 Laboratory of Virology, Institute of Biomedical Sciences, Federal University of Uberlandia, Uberlandia, Minas Gerais, Brazil respiratory disease, with severe cases leading to pneumonia, kidney failure, and even death. The severe respiratory illness caused by the COVID-19 was first detected in Wuhan, Hubei, China, and infections have spread worldwide [2]. Currently, the available COVID-19 genome sequences from clinical samples suggest that this viral emergence is related to bat coronaviruses [3]. Although the coronavirus infection in humans frequently presents with mild severity, the betacoronavirus infection of either the severe acute respiratory syndrome coronavirus (SARS-CoV) [4] or the Middle East respiratory syndrome coronavirus (MERS-CoV) [5] resulted in higher mortality rates [6]. Given the novelty of COVID-19, some characteristics of the virus remain yet unknown. The COVID-19 outbreak serves as both a reminder and an opportunity to assist. Considering that COVID-19 was recently identified in saliva of infected patients [7], the COVID-19 outbreak is a reminder that dental/oral and other health professionals must always be diligent in protecting against the spread of infectious disease, and it provides a chance to determine if a non-invasive saliva diagnostic for COVID-19 could assist in detecting such viruses and reducing the spread.

The Chinese Centre for Disease Control and Prevention isolated the COVID-19. It published the viral genome sequence data immediately in international database banks GenBank and the Global Initiative on Sharing All Influenza Data (GISAID) [8, 9]. This action enabled laboratories in several countries to develop unique PCR tests focusing on the diagnosis of COVID-19 [8, 10]. Currently, the COVID-19 transmission routes are still to be determined, but human-to-human transmission has been confirmed [10, 11]. The laboratory diagnostic tests should be performed using nasopharyngeal, oropharyngeal, and blood samples. Expectorated sputum and other specimens in severe respiratory disease should be considered as lower respiratory tract samples [2, 12, 13]. Several potential scenarios of COVID-19 transmission have been described. The transmission via contact with droplets from talking, coughing, sneezing (related to human respiratory activities), and aerosols generated during clinical procedures is expected, as it would be for other respiratory 
infections. The origin of droplets can be nasopharyngeal or oropharyngeal, normally associated with saliva. Larger droplets could contribute to viral transmission to subjects nearby, and, on the other side, the long-distance transmission is possible with smaller droplets infected with air-suspended viral particles [14]. Considering that laboratory diagnostic tests are also performed in blood samples, the transmission by contaminated blood should also be considered. In this context, healthcare workers, such as dentists, may be unknowingly providing direct care for infected, but not yet diagnosed COVID-19 patients, or those considered to be suspected cases for surveillance $[12,13]$. Asymptomatic infections seem to be possible [15] and transmission may occur before the disease symptoms appear. A recent clinical study indicates that $29 \%$ of 138 hospitalized patients with COVID-19infected pneumonia in Wuhan, China, are healthcare workers [16]. As in bronchoscopy [17], inhalation of airborne particles and aerosols produced during dental procedures on patients with COVID-19 can be a high-risk procedure in which dentists are directly and closely exposed to this virus. Therefore, it is crucial for dentists to refine preventive strategies to avoid the COVID-19 infection by focusing on patient placement, hand hygiene, all personal protective equipment (PPE), and caution in performing aerosol-generating procedures. The Interim Guidance for Healthcare Professionals from CDC has been updated, and it is subject to change as additional information on COVID-19 infection and transmission becomes available.

Diagnosis of COVID-19 can theoretically be performed using salivary diagnosis platforms. Some virus strains have been detected in saliva as long as 29 days after infection [18, 19], indicating that a non-invasive platform to rapidly differentiate the biomarkers using saliva could enhance disease detection. [20] Saliva samples could be collected in patients who present with oropharyngeal secretions as a symptom $[12,13]$. Bearing in mind the requirement of a close contact between healthcare workers and infected patients to collect nasopharyngeal or oropharyngeal samples, the possibility of a saliva self-collection can strongly reduce the risk of COVID-19 transmission. Besides, the nasopharyngeal and oropharyngeal collection promotes discomfort and may promote bleeding especially in infected patients with thrombocytopenia. The sputum of a lower respiratory tract was produced by only $28 \%$ of COVID-19 patients, which indicates a strong limitation as specimen to diagnostic evaluation [7]. We suggest that there is a minimum of three different pathways for COVID-19 to present in saliva: firstly, from COVID-19 in the lower and upper respiratory tract $[2,3]$ that enters the oral cavity together with the liquid droplets frequently exchanged by these organs. Secondly, COVID-19 present in the blood can access the mouth via crevicular fluid, an oral cavity-specific exudate that contains local proteins derived from extracellular matrix and serum-derived proteins [21]. Finally, another way for COVID19 to occur in the oral cavity is by major- and minor-salivary gland infection, with subsequent release of particles in saliva via salivary ducts. It is essential to point out that salivary gland epithelial cells can be infected by SARS-CoV a short time after infection in rhesus macaques, suggesting that salivary gland cells could be a pivotal source of this virus in saliva [22]. Additionally, the production of SARS-CoV-specific secretory immunoglobulin A ( $\operatorname{IgA}$ ) in the saliva of animal models intranasally immunized was previously shown [23]. Considering the similarity of both strains, we speculate that salivary diagnosis of COVID-19 could also be performed using specific antibodies to this virus.

Further studies are needed to investigate the potential diagnostic of COVID-19 in saliva and its impact on transmission of this virus, which is crucial to improve effective strategies for prevention, especially for dentists and healthcare professionals that perform aerosol-generating procedures. Saliva can have a pivotal role in the human-to-human transmission, and salivary diagnostics may provide a convenient and costeffective point-of-care platform for COVID-19 infection.

Funding information This research was supported by the Canadian Institutes of Health Research (CIHR grant nos. 106657 and 97577). The authors received financial support from the Royal Society - Newton Advanced Fellowship (grant reference NA 150195) and FAPEMIG (Minas Gerais Research Foundation - SICONV 793988/2013; APQ-02872-16 and APQ-03385-18). ACGJ received productivity fellowship (311219/2019-5) from the CNPq (National Counsel of Technological and Scientific Development). The Brazilian funding agencies CNPq, CAPES (Coordination for the Improvement of Higher Education), and FAPEMIG provide financial support to the National Institute of Science and Technology in Theranostics and Nanobiotechnology - INCT-Teranano (CNPq-465669/2014-0).

\section{Compliance with ethical standards}

Competing interests The authors declare that they have no competing interests.

\section{References}

1. The Lancet (2020) Emerging understandings of COVID-19. Lancet. 395(10221):311. https://doi.org/10.1016/S0140-6736(20) 30186-0

2. Zhu N, Zhang D, Wang W et al (2019) China Novel Coronavirus Investigating and Research Team. A novel coronavirus from patients with pneumonia in China. N Engl J Med:2020. https://doi. org/10.1056/NEJMoa2001017

3. Zhou P, Yang XL, Wang XG et al (2020) A pneumonia outbreak associated with a new coronavirus of probable bat origin. Nature. https://doi.org/10.1038/s41586-020-2012-7

4. Ksiazek TG, Erdman D, Goldsmith CS et al (2003) A novel coronavirus associated with severe acute respiratory syndrome. N Engl J Med 348(20):1953-1966

5. de Groot RJ, Baker SC, Baric RS, Brown CS, Drosten C, Enjuanes L, Fouchier RA, Galiano M, Gorbalenya AE, Memish ZA, Perlman S, Poon LL, Snijder EJ, Stephens GM, Woo PC, Zaki AM, Zambon M, Ziebuhr J (2013) Middle East respiratory syndrome coronavirus (MERS-CoV): announcement of the Coronavirus Study Group. J Virol 87(14):7790-7792. https://doi.org/10.1128/JVI.01244-13 
6. Hui DSC, Zumla A (2019) Severe acute respiratory syndrome: historical, epidemiologic, and clinical features. Infect Dis Clin N Am 33(4):869-889. https://doi.org/10.1016/j.idc.2019.07.001

7. To KK, Tsang OT, Chik-Yan Yip C et al (2020) Consistent detection of 2019 novel coronavirus in saliva. Clin Infect Dis. https://doi.org/10. 1093/cid/ciaal49

8. Huang C, Wang Y, Li X et al (2020) Clinical features of patients infected with 2019 novel coronavirus in Wuhan, China. Lancet S0140-6736(20):30183-30185. https://doi.org/10.1016/S01406736(20)

9. World Health Organization - WHO (2020a) Emergencies preparedness, response. Pneumonia of unknown origin - China disease outbreak news; 12 January, Accessed 12 Jan 2020. Available at: https:// www.who.int/csr/don/12-january-2020-novel-coronavirus-china/en/

10. Wu A, Peng Y, Huang B et al (2020) Genome composition and divergence of the novel coronavirus (COVID-19) originating in China. Cell Host Microbe S1931-3128(20):30072-X. https://doi. org/10.1016/j.chom.2020.02.001

11. Shu Y, McCauley J (2017) GISAID: global initiative on sharing all influenza data - from vision to reality. Euro Surveill 22(13). https:// doi.org/10.2807/1560-7917.ES.2017.22.13.30494

12. ECDC - European Centre for Disease Prevention and Control; European surveillance for human infection with novel coronavirus (COVID-19); 22 January, Accessed 28 Jan 2020. Available at: https://www.ecdc.europa.eu/en/european-surveillance-humaninfection-novel-coronavirus-COVID-19

13. World Health Organization-WHO (2020) Global surveillance for human infection with novel coronavirus (COVID-19) Interim guidance. 21 January, Accessed 28 Jan 2020. Available at: https://www. who.int/docs/default-source/coronaviruse/20200121-globalsurveillance-for-COVID-19.pdf

14. Xie X, Li Y, Sun H, Liu L (2009) Exhaled droplets due to talking and coughing. J R Soc Interface 6(Suppl 6):S703-S714. https://doi. org/10.1098/rsif.2009.0388.focus

15. Chan JF, Yuan S, Kok KH et al (2020) A familial cluster of pneumonia associated with the 2019 novel coronavirus indicating person-to-person transmission: a study of a family cluster. Lancet. https://doi.org/10.1016/S0140-6736(20)30154-9
16. Wang D, Hu B, Hu C et al (2020) Clinical characteristics of 138 hospitalized patients with 2019 novel coronavirus-infected pneumonia in Wuhan, China. JAMA. https://doi.org/10.1001/jama. 2020.1585

17. Group of Interventional Respiratory Medicine, Chinese Thoracic Society (2020) [Expert consensus for bronchoscopy during the epidemic of 2019 Novel Coronavirus infection (Trial version)]. 43(0):E006. doi: https://doi.org/10.3760/cma.j.issn.1001-0939.2020.0006

18. Barzon L, Pacenti M, Berto A, Sinigaglia A, Franchin E, Lavezzo E, Brugnaro $P$, Palù $G$ (2016) Isolation of infectious Zika virus from saliva and prolonged viral RNA shedding in a traveller returning from the Dominican Republic to Italy, January 2016. Euro Surveill 21(10): 30159. https://doi.org/10.2807/1560-7917.ES.2016.21.10.30159

19. Zuanazzi D, Arts EJ, Jorge PK, Mulyar Y, Gibson R, Xiao Y, Bringel Dos Santos M, Machado MAAM, Siqueira WL (2017) Postnatal identification of zika virus peptides from saliva. J Dent Res 96(10):1078 1084. https://doi.org/10.1177/0022034517723325

20. Segal A, Wong DT (2008) Salivary diagnostics: enhancing disease detection and making medicine better. Eur J Dent Educ 12(Suppl 1):22-29. https://doi.org/10.1111/j.1600-0579.2007.00477.x

21. Silva-Boghossian CM, Colombo AP, Tanaka M et al (2013) Quantitative proteomic analysis of gingival crevicular fluid in different periodontal conditions. PLoS One 8(10):e75898. https://doi. org/10.1371/journal.pone.0075898

22. Liu L, Wei Q, Alvarez X et al (2011) Epithelial cells lining salivary gland ducts are early target cells of severe acute respiratory syndrome coronavirus infection in the upper respiratory tracts of rhesus macaques. J Virol 85(8):4025-4030. https://doi.org/10.1128/JVI.02292-10

23. Lu B, Huang Y, Huang L, Li B, Zheng Z, Chen Z, Chen J, Hu Q, Wang H (2010) Effect of mucosal and systemic immunization with virus-like particles of severe acute respiratory syndrome coronavirus in mice. Immunology. 130(2):254-261. https://doi.org/10.1111/ j.1365-2567.2010.03231.x

Publisher's note Springer Nature remains neutral with regard to jurisdictional claims in published maps and institutional affiliations. 